学位論文

Paraquat toxicity is attenuated by 4-phenylbutyrate-induced phosphorylation of ERK2 via PI3K in A549 cells

(4-フェニル酪酸は ERK2 のリン酸化を介してパラコート毒性を抑制する)

\title{
保科 千里
}

(大村友博、奥田勝博、田中宏樹、浅利 優、磯崎翔太郎、

堀岡希衣、山田ひろみ、土井大輝、塩野 寬、松原和夫、清水惠子) 


\title{
Paraquat toxicity is attenuated by 4-phenylbutyrate-induced phosphorylation of ERK2 via PI3K in A549 cells
}

\author{
Chisato Hoshina ${ }^{a}$, Tomohiro Omura ${ }^{b}$, Katsuhiro Okuda ${ }^{a}{ }^{*}$, Hiroki Tanaka a \\ Masaru Asari a , Shotaro Isozaki ${ }^{a}$, Kie Horioka ${ }^{a}$, Hiromi Yamada a , Hiroki Doi a , \\ Hiroshi Shiono $^{\text {a }}$, Kazuo Matsubara ${ }^{\text {b }}$, Keiko Shimizu ${ }^{\text {a }}$ \\ a Department of Legal Medicine, Asahikawa Medical University, Asahikawa, Hokkaido, 070-8510, Japan \\ ${ }^{\mathrm{b}}$ Department of Clinical Pharmacology and Therapeutics, Kyoto University Hospital, Kyoto, Kyoto, 606-8507, Japan
}

\section{A R T I C L E I N F O}

\section{Article history:}

Received 4 June 2018

Accepted 15 June 2018

\section{Keywords:}

Paraquat

4-Phenylbutyrate

ERK

PI3K

Akt

A549 cell

\begin{abstract}
A B S T R A C T
Paraquat (PQ) is a widely used herbicide in the world despite being highly toxic to humans. PQ causes fatal damage to multiple organs, especially the lungs. While oxidative stress is the main toxic mechanism of $\mathrm{PQ}$ there is no established standard therapy for $\mathrm{PQ}$ poisoning. In this study, we investigated the cytoprotective effect of 4-phenylbutyrate (4PBA) on PQ toxicity in human lung adenocarcinoma A549 cells. Phosphorylation levels of major survival signaling kinases Akt and ERK, as well as expression levels of antioxidant enzymes catalase and superoxide dismutase 2 (SOD2) were examined. The cytoprotective mechanism of $4 \mathrm{PBA}$ against $\mathrm{PQ}$ was compared with the antioxidant reagent trolox. We demonstrated that both 4PBA and trolox attenuated PQ toxicity, but their mechanisms were different. 4PBA increased ERK2 phosphorylation levels, which could be inhibited by the PI3K inhibitor LY294002. The cytoprotective effect of 4PBA was also inhibited by LY294002. Catalase expression levels were increased by 4PBA, although this increase was not inhibited by LY294002. 4PBA did not increase SOD2 expression. Trolox did not affect phosphorylation of Akt or ERK, or the expression of antioxidant enzymes. These results suggest that 4PBA attenuated PQ cytotoxicity by ERK2 activation via PI3K. Our study may provide new findings for understanding the molecular mechanism underlying cytoprotection by 4PBA, as well as new therapeutic targets for PQ poisoning.
\end{abstract}

() 2018 Elsevier Inc. All rights reserved.

\section{Introduction}

Paraquat (PQ) is a widely used herbicide in the world despite being highly toxic to humans. Acute toxicity of PQ causes fatal damage to multiple organs, especially the lungs, and causes disorders such as pulmonary fibrosis [1]. While oxidative stress is the main toxic mechanism of PQ [2,3], there is no established standard therapy for PQ poisoning.

We previously reported that sodium tauroursodeoxycholate protects cells from PQ toxicity through chemical chaperone activity [4]. 4-Phenylbutyrate (4PBA) is used for its ammonia-scavenging activity to treat urea cycle disorders [5,6], prevents ER stress by modifying unfolded proteins as a chemical chaperone, and regulates

Abbreviations: ERK, extracellular signal-regulated kinase; PI3K, phosphatidylinositol 3-kinase; MEK, MAPK-ERK kinase; MAPK, mitogen-activated protein kinase

* Corresponding author.

E-mail address: k-okuda@asahikawa-med.ac.jp (K. Okuda). gene expression as a histone deacetylase inhibitor. Notably, these properties are similar to sodium tauroursodeoxycholate [7-9]. While 4PBA has been widely studied as chemical chaperone and histone deacetylase inhibitor in pathological models such as those for Alzheimer's disease, Parkinson's disease and diabetic nephropathy [10-12], its antioxidant action and survival signaling pathway remain controversial; thus, more research is needed [13,14].

In this study, we tried to clarify whether survival signal transduction is involved in the cytoprotective mechanism of 4PBA against PQ toxicity. First, we confirmed the cytoprotective effect of 4PBA against PQ toxicity in the A549 cell line, a commonly used model of alveolar epithelial cells [15-17]. Next, we sought to examine whether 4PBA influenced major cell survival signaling pathways PI3K/Akt and MEK/ERK in the presence of PQ. In addition, expression levels of antioxidant enzymes catalase and superoxide dismutase 2 (SOD2) were examined. Finally, the cytoprotective mechanism of 4PBA against PQ was compared with the antioxidant reagent trolox. 


\section{Materials and methods}

\subsection{Reagents and antibodies}

1,1'-Dimethyl-4,4'-bipyridinium chloride (PQ) was purchased from Kanto Kagaku (Tokyo, Japan). Sodium 4-phenylbutyrate (4PBA) and 3-(4, 5-dimethylthiazol-2-yl)-2, 5-diphenyl tetrazolium bromide (MTT) were obtained from Sigma-Aldrich (St. Louis, MO, USA). Trolox, LY294002, and U0126 were from Cayman Chemical (Ann Arbor, MI, USA).

Primary antibodies for phospho-Akt ( $p$-Akt; 1:1000, \#9271), Akt (1:2000, \#4691), phospho-p44/42 MAPK ( $p$-ERK 1/2; 1:1000, \#4370), p44/42 MAPK (ERK 1/2; 1:2000, \#4695), catalase (1:1000, \#12980), and SOD2 (1:2000, \#13141) were purchased from Cell Signaling Technology (Danvers, MA, USA). Anti- $\beta$-actin (1:20000, A1978) was a product of Sigma-Aldrich. For secondary antibodies, anti-rabbit (1:10000 or 1:20000, \#7074) and anti-mouse (1:50000, NA931) were purchased from Cell Signaling Technology and GE Healthcare (Little Chalfont, UK).

\subsection{Cell culture}

Human lung adenocarcinoma A549 cells were obtained from American Type Culture Collection (Manassas, VA, USA). Cells were maintained in Dulbecco's Modified Eagle's Medium (High Glucose DMEM; Nacalai Tesque, Kyoto, Japan) containing 10\% heatinactivated fetal bovine serum (BioWest, Nuaillé, France) in a humidified atmosphere with $5 \% \mathrm{CO}_{2}$ at $37^{\circ} \mathrm{C}$. Cells were seeded on 24well plates $\left(1.5 \times 10^{5}\right.$ cells/well, for MTT assay) or $35-\mathrm{mm}$ dishes $\left(6.0 \times 10^{5}\right.$ cells/dish, for western blotting). Reagents were added $24 \mathrm{~h}$ later. All treatment reagents contained 0.01\% DMSO as a vehicle.

\subsection{MTT assay}

MTT assays were performed to evaluate cell viability. The MTT assay is a method for measuring aerobic succinate-MTT reductase activity in active mitochondria [18]. Therefore, it can be used to assess cytotoxicity, proliferation or activation [19]. We expressed cytotoxicity as cell viability.

MTT was dissolved in phosphate-buffered saline at $5 \mathrm{mg} / \mathrm{mL}$ and filtered through a $0.45-\mu \mathrm{m}$ filter (Millex-HV; Merck Millipore, Darmstadt, Germany). After $24 \mathrm{~h}$ of drug treatment, $50 \mu \mathrm{L}$ MTT solution was added to each well and the plate was incubated for $40 \mathrm{~min}$ at $37^{\circ} \mathrm{C}$. Then, the medium was discarded and $700 \mu \mathrm{L}$ of DMSO was added to each well to dissolve stained cells. The absorbance was measured at a wavelength of $560 \mathrm{~nm}$ with background subtraction at $630 \mathrm{~nm}$ using a microplate reader (Multiskan JX; Thermo Labsystem, Helsinki, Finland) to calculate relative cell viability.

\subsection{Western blotting}

Cell samples were prepared as previously described [4] (with $140-200 \mu \mathrm{L}$ of lysis buffer). Equal amounts of total protein (5 or $15 \mu \mathrm{g}$ ) were separated by electrophoresis on 10\% SDSpolyacrylamide gel (ATTO, Tokyo, Japan) and transferred onto a PVDF membrane (Immobilon-P; Merck Millipore). The membrane was sequentially treated with Block Ace (DS Pharma Biomedical, Osaka, Japan) and incubated overnight at $4{ }^{\circ} \mathrm{C}$ with primary antibodies in $10 \mathrm{mM}$ Tris-buffered saline ( $\mathrm{pH} 7.4$ ) containing $0.1 \%$ Tween 20 (TBST). The membrane was then washed with TBST and probed with secondary antibody in TBST for $1 \mathrm{~h}$ at room temperature. The washing procedure was repeated before the membrane was treated with a chemiluminescent reagent (ECL Prime, GE
Healthcare). Protein expression was visualized using a LumiViewer EX140 (AISIN, Aichi, Japan) and quantified by LumiVision Analyzer140 (AISIN).

\subsection{Statistical analysis}

Data are expressed as mean \pm SEM. Statistical analysis was performed using the Tukey-Kramer's test. Significance was accepted when the $p$-value was less than 0.05 .

\section{Results}

\subsection{PBA and trolox attenuated PQ cytotoxicity}

MTT assay was performed to assess the cytoprotective effect of 4PBA and trolox. Cell viability after treatment with $250 \mu \mathrm{M}$ PQ for $24 \mathrm{~h}$ was reduced to approximately $70 \%$ compared with control in A549 cells. However, viability was recovered to approximately $90 \%$ by concomitant treatment of PQ with $5 \mathrm{mM} 4 \mathrm{PBA}$ or $1 \mathrm{mM}$ trolox (Fig. 1A and B). These results indicate that 4PBA and trolox significantly attenuated cell damage induced by $P Q$.

\subsection{LY294002 inhibited the cytoprotective effect of $4 P B A$}

Involvement of major intracellular survival signaling pathways PI3K/Akt and MEK/ERK in the mechanism by which 4PBA and trolox elicit cytoprotective effects was investigated. Either $10 \mu \mathrm{M}$ LY294002 (a PI3K inhibitor) or $10 \mu \mathrm{M}$ U0126 (a MEK inhibitor) was incubated with PQ and 4PBA or trolox for $24 \mathrm{~h}$ before the MTT assay was performed. The cytoprotective effect of $4 \mathrm{PBA}$ on PQ toxicity was inhibited by co-treatment with LY294002. However, this phenomenon was not observed when cells were treated with U0126 (Fig. 1C). Both LY294002 and U0126 had no effect on cytoprotection by trolox (Fig. 1D).

\subsection{PBA enhanced phosphorylation levels of ERK2 against $P Q$ cytotoxicity}

To confirm the involvement of PI3K/Akt and MEK/ERK pathways in the mechanism of 4PBA-elicited cytoprotection, phosphorylation levels of Akt and ERK were measured using western blotting and compared with trolox treatments. The phosphorylation level of ERK2 was increased $3 \mathrm{~h}$ after treatment with PQ and 4PBA, and was inhibited by LY294002 (Fig. 2B). The phosphorylation level of ERK1 was not increased. The phosphorylation level of Akt tended to increase, although there was no statistically significant difference (Fig. 2A). After $24 \mathrm{~h}$ of treatment, phosphorylation levels of ERK and Akt were not different between PQ only and PQ with 4PBA (Fig. 2C and D). Exposure to PQ and trolox did not affect those levels (Fig. 2E and F). Phosphorylation levels of Akt were increased in the presence of U0126 compared with the condition without inhibitors (Fig. 2A, C and E).

\subsection{PBA induced up-regulation of catalase against PQ cytotoxicity}

To examine the involvement of antioxidant enzymes in the mechanism of 4PBA and trolox cytoprotective effects, expression of catalase and SOD2 proteins were measured using western blotting. Catalase expression showed a tendency to decrease after PQ treatment (Fig. 3A, C and E). Co-treatment of PQ and 4PBA increased catalase expression after $24 \mathrm{~h}$, however this up-regulation was not inhibited by either LY294002 or U0126 (Fig. 3C). SOD2 expression showed no statistically significant difference in response to 4PBA (Fig. 3B and D). Moreover, exposure to PQ and trolox did not affect those levels (Fig. 3E and F). 
A

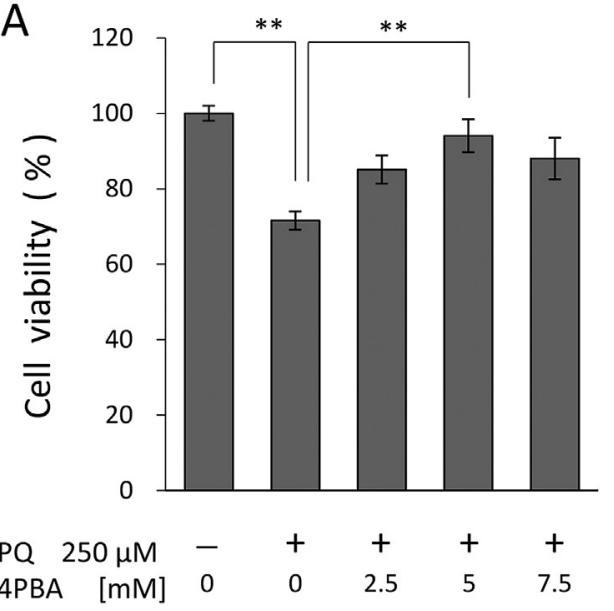

B

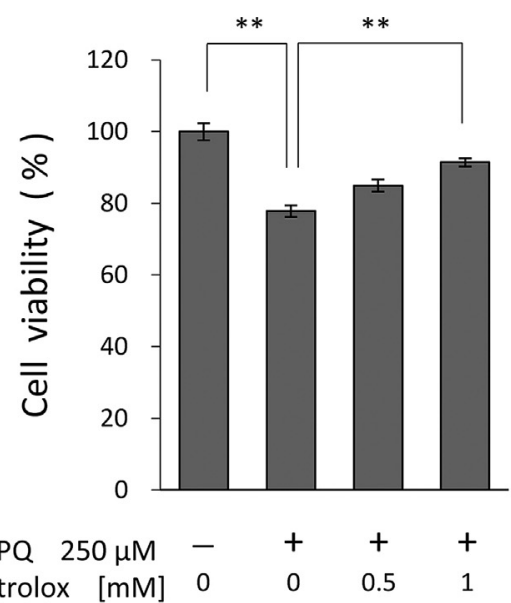

C

$\square \mathrm{PQ}(-) \quad \square \mathrm{PQ} 250 \mu \mathrm{M}$
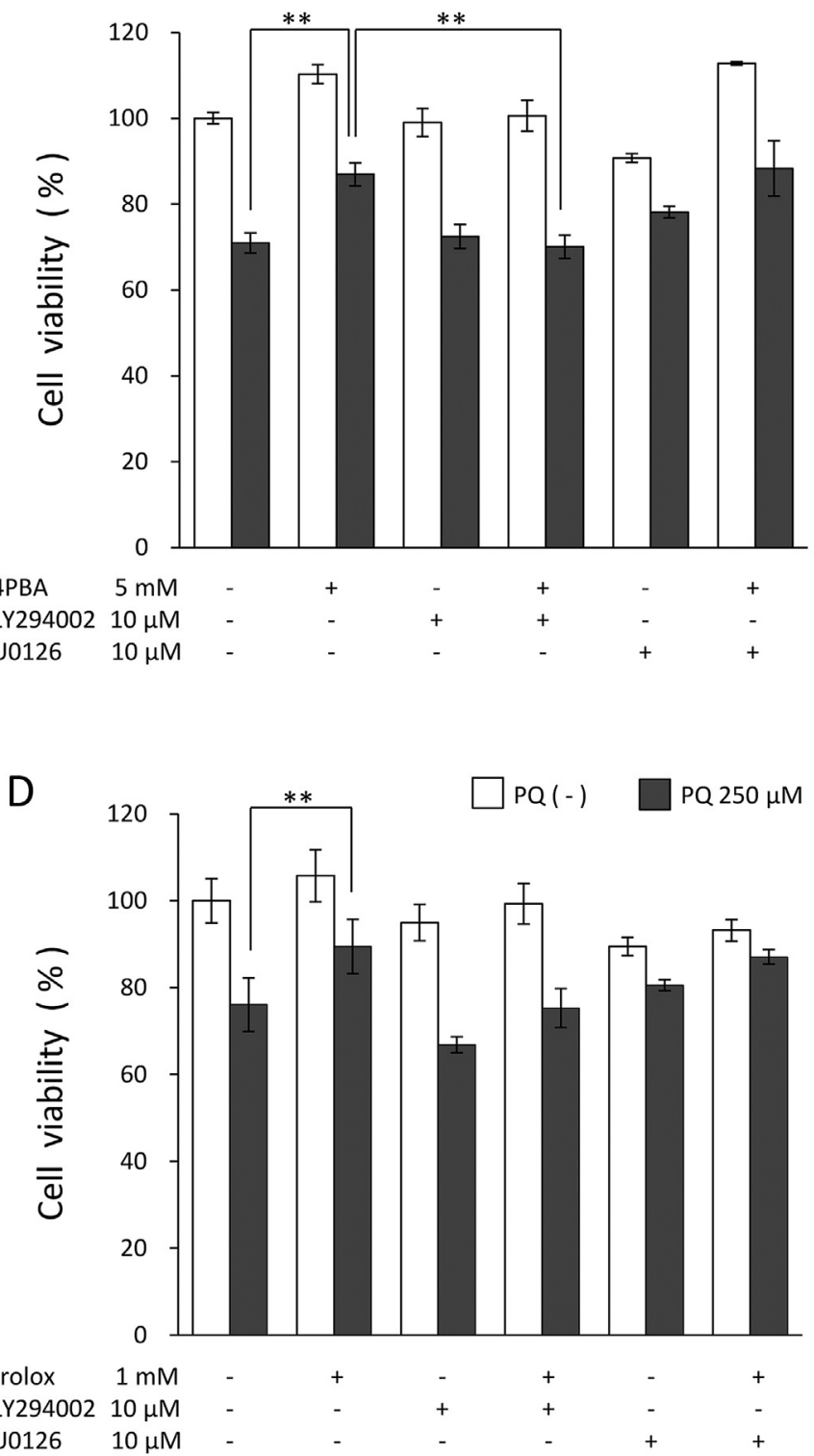


\section{3 hours}

A

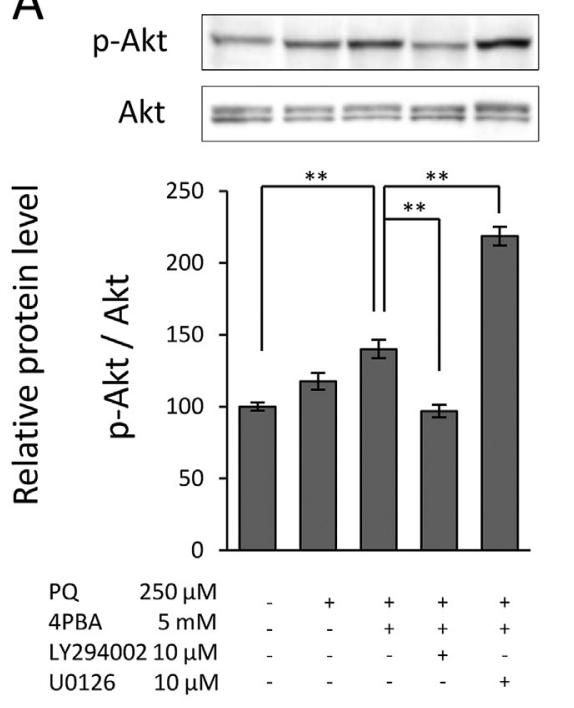

C

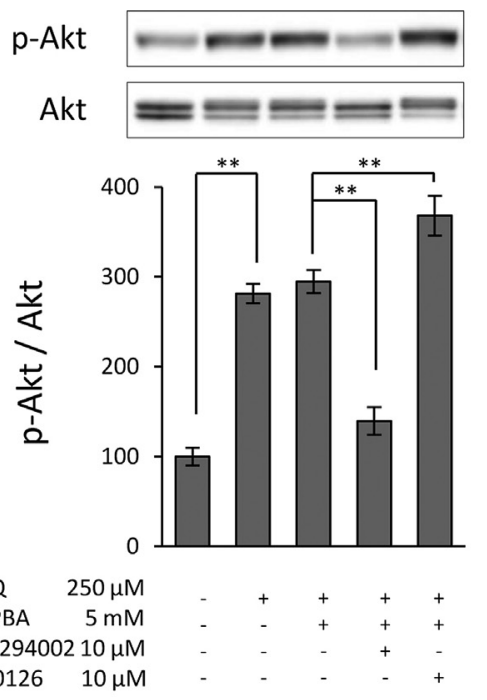

E
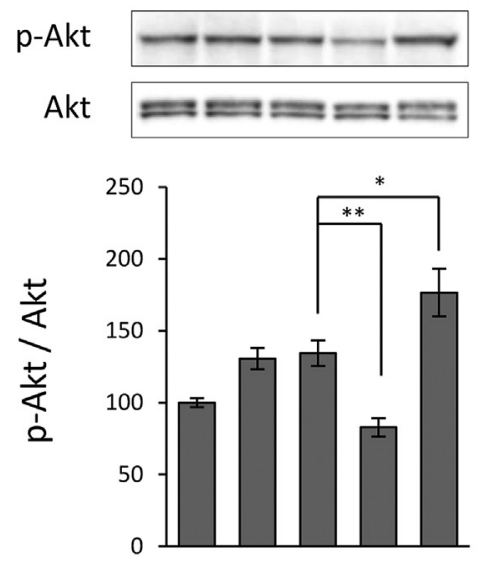

$\mathrm{PQ} \quad 250 \mu \mathrm{M}$

trolox $1 \mathrm{mM}$
LY294002 $10 \mu \mathrm{M}$ U0126 $10 \mu \mathrm{M}$
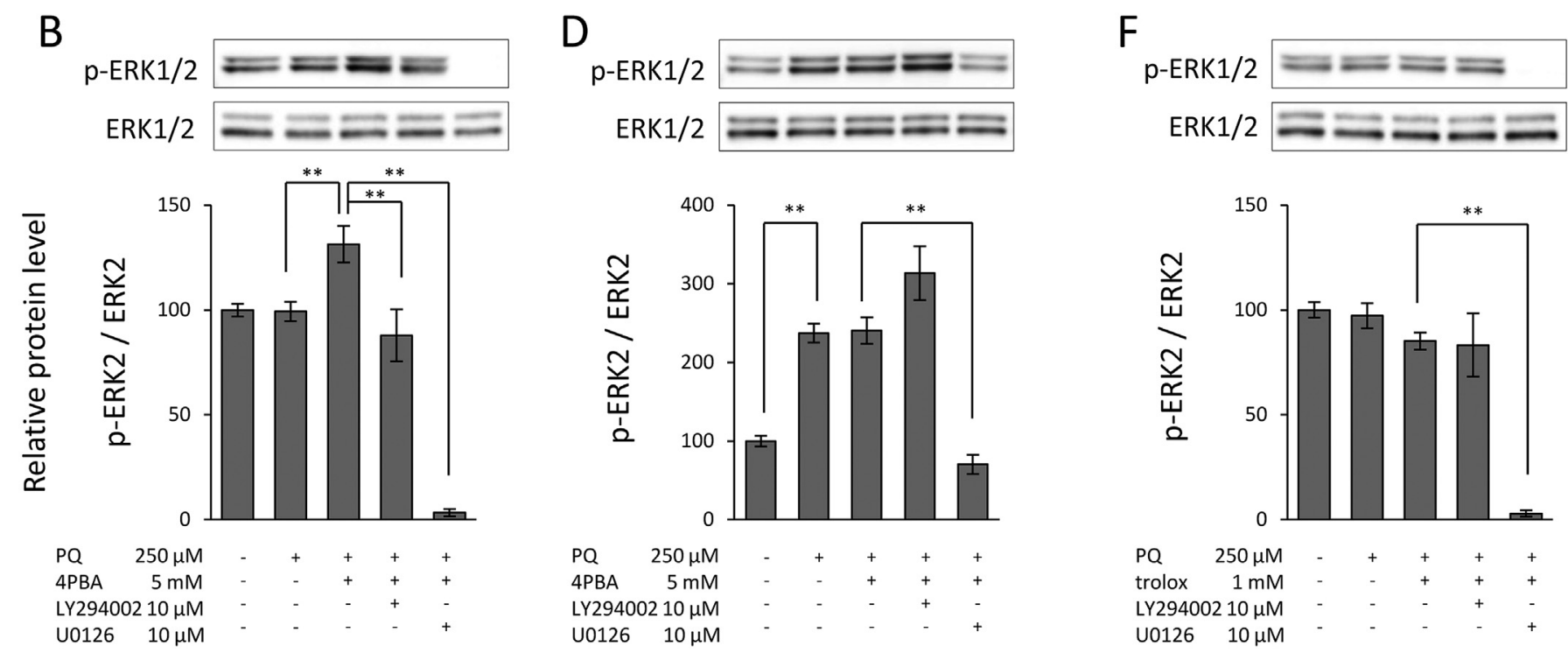

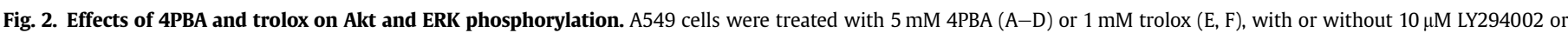

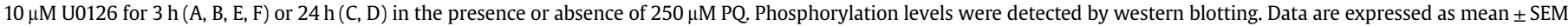
of at least three independent experiments. Differences where $p$-values $<0.05\left(^{*}\right)$ and $p$-values $<0.01(* *)$ were significant by Tukey-Kramer's test.

\section{Discussion}

In this study, we demonstrated that both 4PBA and trolox attenuated PQ toxicity in A549 cells, but their mechanisms were different. 4PBA affected the intracellular survival signaling pathway MEK/ERK in the presence of $\mathrm{PQ}$ while trolox did not show any effect.

4PBA increased ERK2 phosphorylation levels in the presence of PQ and this increase was inhibited by the PI3K inhibitor LY294002. The cytoprotective effect of 4PBA was completely inhibited by
LY294002 according to the MTT assay. These results suggest that ERK2 phosphorylation plays a key role in 4PBA-induced cytoprotection via PI3K. This is consistent with a previous report indicating the involvement of PI3K in ERK phosphorylation [20].

Temporal regulation of ERK is an important factor in cellular responses [21]. The effect of ERK depends on whether activation is transient or persistent [22-24]. Increased ERK2 phosphorylation was observed $3 \mathrm{~h}$ after co-treatment with PQ and 4PBA compared with PQ treatment alone, but not after $24 \mathrm{~h}$. In contrast, treatment with PQ only increased ERK phosphorylation for $24 \mathrm{~h}$. Although

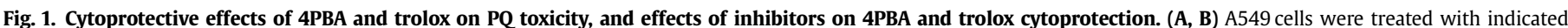

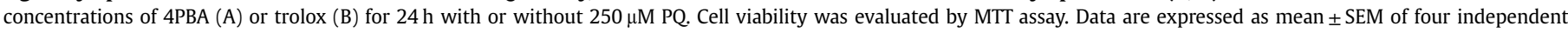

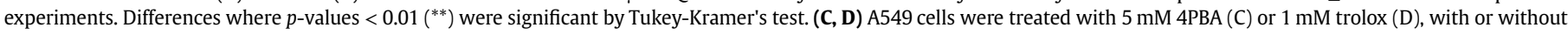

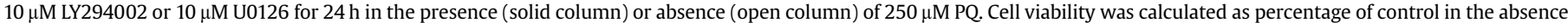

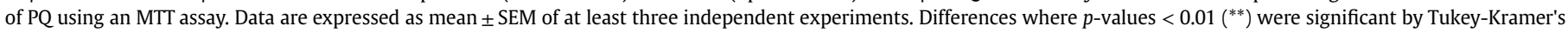
test when compared with the corresponding PQ-treated group. 
A

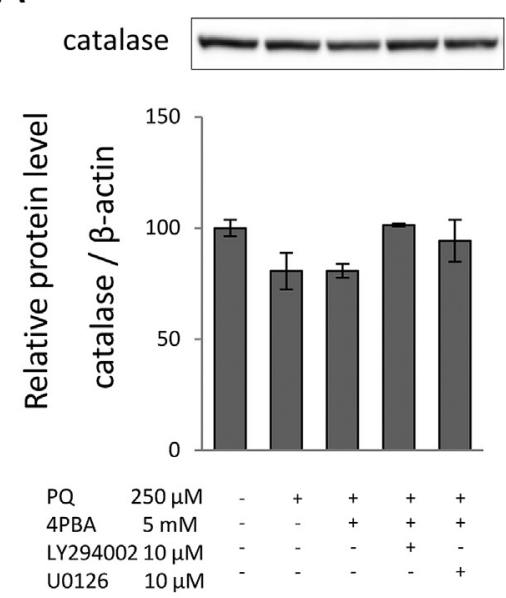

B

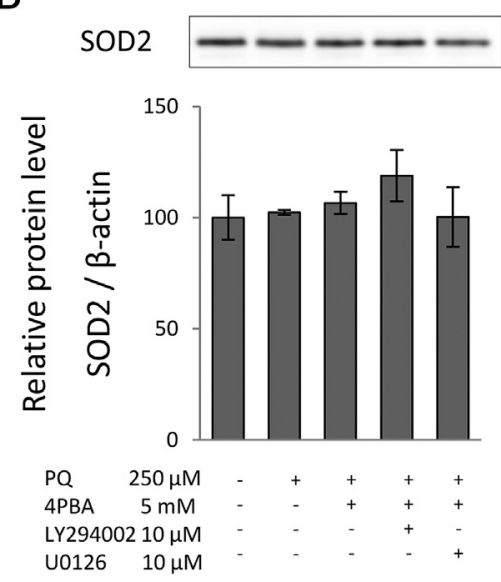

$\beta$-actin
C
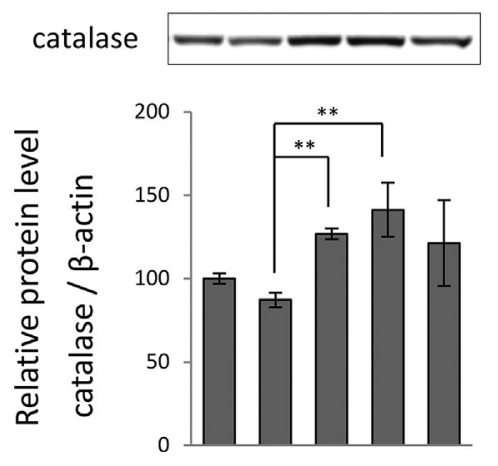

$\mathrm{E}$
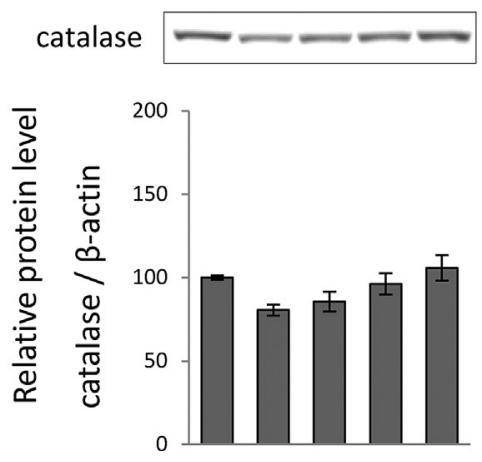

$\begin{array}{lrlllll}\mathrm{PQ} & 250 \mu \mathrm{M} & - & + & + & + & + \\ \text { trolox } 1 \mathrm{mM} & - & - & + & + & + \\ \text { LY294002 } 10 \mu \mathrm{M} & - & - & - & + & - \\ \text { U0126 } 10 \mu \mathrm{M} & - & - & - & - & +\end{array}$

$\mathrm{F}$

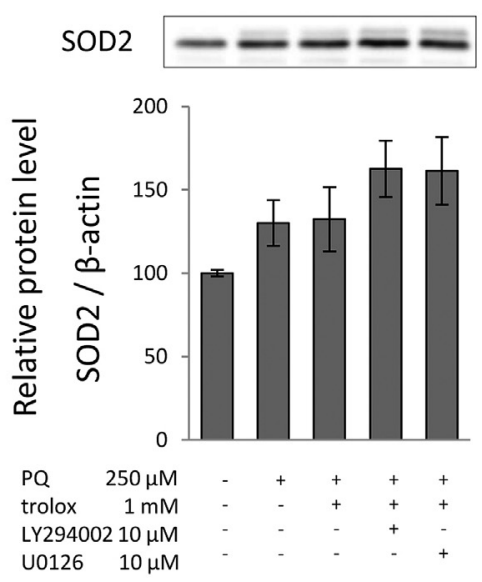

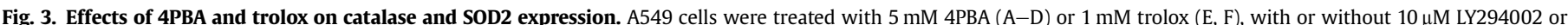

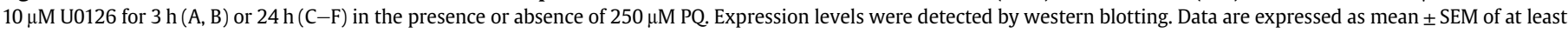
three independent experiments. Differences where $p$-values $<0.01\left({ }^{* *}\right)$ were significant by Tukey-Kramer's test.

ERK is known as a MAP kinase that transduces survival signals [25], it also induces apoptosis [26]. ERK may be phosphorylated as a toxic mechanism of PQ [27,28]. Therefore, 4PBA is considered to phosphorylate ERK2 before activation by $\mathrm{PQ}$. Our data suggest the possibility that 4PBA induced transient activation of ERK2 to attenuate PQ cytotoxicity.

Upon inhibition of ERK2 phosphorylation by the MEK inhibitor U0126, phosphorylation of Akt was significantly increased. Thus, we considered that when ERK activation was inhibited, phosphorylation of Akt compensated through cross-talk between MEK/ERK and PI3K/Akt pathways [29-31] to at least partially protect cells.

Expression of the antioxidant enzyme catalase was increased by $4 \mathrm{PBA}$ in the presence of $\mathrm{PQ}$. Catalase, an enzyme that decomposes hydrogen peroxide into oxygen and water [32], is presumed to reduce oxidative stress caused by PQ. Although catalase expression levels did not decrease, the cytoprotective effect of 4PBA was decreased by LY294002. One of the other antioxidant enzyme, SOD2, which decomposes superoxide anions into hydrogen peroxide [32], was not increased by 4PBA. These results raise the possibility that an antioxidant effect may not be involved in the mechanism by which 4PBA protects cells against PQ toxicity. However, catalase gene expression is reportedly increased in cellular cytoprotective responses to PQ toxicity [33]. Thus, further investigation is required to confirm the relationship between antioxidant enzymes and the cytoprotective effect of 4PBA. Indeed, survival signal transduction and catalase up-regulation may be mediated by the chemical chaperone activity or histone deacetylase inhibitor activity of $4 \mathrm{PBA}$, hence more research is necessary.

Trolox, an antioxidant derived from water-soluble vitamin E, is commonly used as a standard or positive control in antioxidant assays. Trolox acts as a reducing agent [34]. The mechanisms by which trolox induces antioxidant activity include reduction of reactive oxygen and nitrogen species produced by PQ radicals [2,3], and trolox attenuates PQ cytotoxicity (Fig. 4).

In conclusion, our study suggests that 4PBA enhances phosphorylation of ERK2 via PI3K to attenuate PQ toxicity in A549 cells. 4 PBA also increases catalase expression, although this increase may not be involved in enhanced cell viability. These results may provide new findings for understanding the molecular mechanism by 


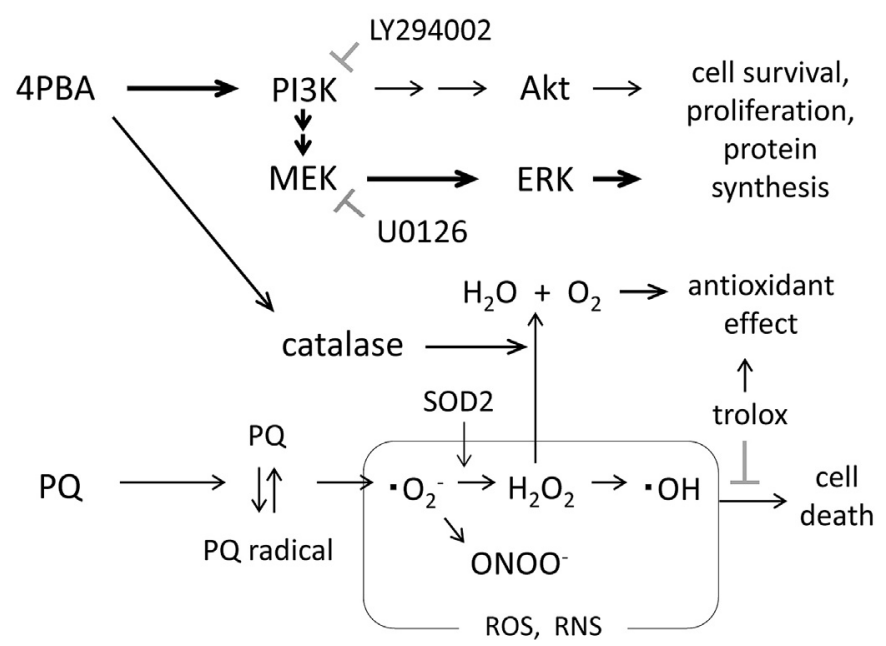

Fig. 4. Potential site of $4 P B A$ action in attenuating PQ cytotoxicity. 4PBA attenuates PQ cytotoxicity through ERK2 activation via PI3K. When ERK2 phosphorylation is inhibited by the MEK inhibitor U0126, Akt is phosphorylated in a compensatory manner and PQ toxicity is attenuated. When PI3K is inhibited by LY294002, both ERK2 and Akt are not phosphorylated and the cytoprotective effect is lost. ROS; reactive oxygen species, RNS; reactive nitrogen species.

which 4PBA elicits cytoprotection, as well as new therapeutic targets for PQ toxicity.

\section{Conflicts of interest}

We have no financial relationships to disclose.

\section{Transparency document}

Transparency document related to this article can be found online at https://doi.org/10.1016/j.bbrc.2018.06.080.

\section{References}

[1] P. Smith, D. Heath, Paraquat lung: a reappraisal, Thorax 29 (1974) 643-653.

[2] R. Franco, S. Li, H. Rodriguez-Rocha, M. Burns, M.I. Panayiotidis, Molecular mechanisms of pesticide-induced neurotoxicity: relevance to Parkinson's disease, Chem. Biol. Interact. 188 (2010) 289-300.

[3] T. Herraiz, N-methyltetrahydropyridines and pyridinium cations as toxins and comparison with naturally-occurring alkaloids, Food Chem. Toxicol. 97 (2016) $23-39$.

[4] T. Omura, M. Asari, J. Yamamoto, K. Oka, C. Hoshina, C. Maseda, T. Awaya, Y. Tasaki, H. Shiono, A. Yonezawa, S. Masuda, K. Matsubara, K. Shimizu, Sodium tauroursodeoxycholate prevents paraquat-induced cell death by suppressing endoplasmic reticulum stress responses in human lung epithelial A549 cells, Biochem. Biophys. Res. Commun. 432 (2013) 689-694.

[5] S.W. Brusilow, Phenylacetylglutamine may replace urea as a vehicle for waste nitrogen excretion, Pediatr. Res. 29 (1991) 147-150.

[6] U.L. Konecki, G.A. Diaz, J.L. Merritt II, A. Feigenbaum, C. Jomphe, J.F. Marier, M. Beliveau, J. Mauney, K. Dickinson, A. Martinez, M. Mokhtarani, B. Scharschmidt, W. Rhead, Ammonia control in children with urea cycle disorders (UCDs); phase 2 comparison of sodium phenylbutyrate and glycerol phenylbutyrate, Mol. Genet. Metabol. 103 (2011) 323-329.

[7] S.F. de Almeida, G. Picarote, J.V. Fleming, M.C. Fonseca, J.E. Azevedo, M. de Sousa, Chemical chaperones reduce endoplasmic reticulum stress and prevent mutant HFE aggregate formation, J. Biol. Chem. 282 (2007) 27905-27912.

[8] X.H. Yao, H.K. Nguyen, B.L.G. Nyomba, Prenatal ethanol exposure causes glucose intolerance with increased hepatic gluconeogenesis and histone deacetylases in adult rat offspring: reversal by tauroursodeoxycholic acid, PLoS One 8 (2013) e59680.

[9] P.S. Kolb, E.A. Ayaub, W. Zhou, V. Yum, J.G. Dickhout, K. Ask, The therapeutic effects of 4-phenylbutyric acid in maintaining proteostasis, Int. J. Biochem. Cell Biol. 61 (2015) 45-52.
[10] A. Ricobaraza, M.C. Tejedor, A.P. Mediavilla, D. Frechilla, J. Del Río, A.G. Osta, Phenylbutyrate ameliorates cognitive deficit and reduces tau pathology in an Alzheimer's disease mouse model, Neuropsychopharmacology 34 (2009) $1721-1732$.

[11] K. Ono, M. Ikemoto, T. Kawarabayashi, M. Ikeda, T. Nishinakagawa, M. Hosokawa, M. Shoji, M. Takahashi, M. Nakashima, A chemical chaperone, sodium 4-phenylbutyric acid, attenuates the pathogenic potency in human alpha-synuclein A30P + A53T transgenic mice, Park. Relat. Disord. 15 (2009) 649-654.

[12] Z.F. Luo, B. Feng, J. Mu, W. Qi, W. Zeng, Y.H. Guo, Q. Pang, Z.L. Ye, L. Liu, F.H. Yuan, Effects of 4-phenylbutyric acid on the process and development of diabetic nephropathy induced in rats by streptozotocin: regulation of endoplasmic reticulum stress-oxidative activation, Toxicol. Appl. Pharmacol. 246 (2010) 49-57.

[13] G. Yang, X. Peng, Y. Hu, D. Lan, Y. Wu, T. Li, L. Liu, 4-Phenylbutyrate benefits traumatic hemorrhagic shock in rats by attenuating oxidative stress, not by attenuating endoplasmic reticulum stress, Crit. Care Med. 44 (2016) e477-e491.

[14] S. Patel, D. Sharma, K. Kalia, V. Tiwari, Crosstalk between endoplasmic reticulum stress and oxidative stress in schizophrenia: the dawn of new therapeutic approaches, Neurosci. Biobehav. Rev. 83 (2017) 589-603.

[15] M. Tomita, T. Okuyama, T. Ishikawa, K. Hidaka, T. Nohno, The role of nitric oxide in paraquat-induced cytotoxicity in the human A549 lung carcinoma cell line, Free Radic. Res. 34 (2001) 193-202.

[16] P. Mitsopoulos, Z.E. Suntres, Cytotoxicity and gene array analysis of alveolar epithelial A549 cells exposed to paraquat, Chem. Biol. Interact. 188 (2010) 427-436.

[17] T.Zerin, Y.S. Kim, S.Y. Hong, H.Y. Song, Protective effect of methylprednisolone on paraquat-induced A549 cell cytotoxicity via induction of efflux transporter P-glycoprotein expression, Toxicol. Lett. 208 (2012) 101-107.

[18] T.F. Slater, B. Sawyer, U. Strauli, Studies on succinate-tetrazolium reductase systems. III. points of coupling of four different tetrazolium salts, Biochim. Biophys. Acta 77 (1963) 383-393.

[19] T. Mosmann, Rapid colorimetric assay for cellular growth and survival: application to proliferation and cytotoxicity assays, J. Immunol. Meth. 65 (1983) 55-63.

[20] M.M. Fung, F. Rohwer, K.L. McGuire, IL-2 activation of a PI3K-dependent STAT3 serine phosphorylation pathway in primary human $\mathrm{T}$ cells, Cell. Signal. 15 (2003) 625-636.

[21] J.C. Chambard, R. Lefloch, J. Pouysségur, P. Lenormand, ERK implication in cell cycle regulation, Biochim. Biophys. Acta 1773 (2007) 1299-1310.

[22] R.D. York, H. Yao, T. Dillon, C.L. Ellig, S.P. Eckert, E.W. McCleskey, P.J.S. Stork, Rap1 mediates sustained MAP kinase activation induced by nerve growth factor, Nature 392 (1998) 622-626.

[23] K. Roovers, G. Davey, X. Zhu, M.E. Bottazzi, R.K. Assoian, Alpha5beta1 integrin controls cyclin D1 expression by sustaining mitogen-activated protein kinase activity in growth factor-treated cells, Mol. Biol. Cell 10 (1999) 3197-3204.

[24] L.O. Murphy, S. Smith, R.H. Chen, D.C. Finger, J. Blenis, Molecular interpretation of ERK signal duration by immediate early gene products, Nat. Cell Biol. 4 (2002) 556-564.

[25] Z. Xia, M. Dichens, J. Raingeaud, R.J. Davis, M.E. Greenberg, Opposing effects of ERK and JNK-p38 MAP kinases on apoptosis, Science 270 (1995) 1326-1331.

[26] T.T.T. Nguyen, E. Tran, T.H. Nguyen, P.T. Do, T.H. Huynh, H. Huynh, The role of activated MEK-ERK pathway in quercetin-induced growth inhibition and apoptosis in A549 lung cancer cells, Carcinogenesis 25 (2004) 647-659.

[27] K. Kobayashi, H. Nojiri, Y. Saita, D. Morikawa, Y. Ozawa, K. Watanabe M. Koike, Y. Asou, T. Shirasawa, K. Yokote, K. Kaneko, T. Shimizu, Mitochondrial superoxide in osteocytes perturbs canalicular networks in the setting of age-related osteoporosis, Sci. Rep. 5 (2015) 9148.

[28] M. Huang, Y.P. Wang, L.Q. Zhu, Q. Cai, H.H. Li, H.F. Yang, MAPK pathway mediates epithelial-mesenchymal transition induced by paraquat in alveolar epithelial cells, Environ. Toxicol. 31 (2016) 1407-1414.

[29] C.F. Yu, Z.X. Liu, L.G. Cantley, ERK negatively regulates the epidermal growth factor-mediated interaction of Gab1 and the phosphatidylinositol 3-kinase, J. Biol. Chem. 277 (2002) 19382-19388.

[30] K.P. Hoeflich, C. O'Brien, Z. Boyd, G. Cavet, S. Guerrero, K. Jung, T. Januario, H. Savage, E. Punnoose, T. Truong, W. Zhou, L. Berry, L. Murray, L. Amler, M. Belvin, L.S. Friedman, M.R. Lackner, In vivo antitumor activity of MEK and phosphatidylinositol 3-kinase inhibitors in basal-like breast cancer models, Clin. Canc. Res. 15 (2009) 4649-4664.

[31] M.C. Mondoza, E. Emrah Er, J. Blenis, The Ras-ERK and PI3K-mTOR pathways: cross-talk and compensation, Trends Biochem. Sci. 36 (2011) 320-328.

[32] J.M. Matés, Effects of antioxidant enzymes in the molecular control of reactive oxygen species toxicology, Toxicology 153 (2000) 83-104.

[33] B. Podder, Y.S. Kim, H.Y. Song, Cytoprotective effect of bioactive sea buckthorn extract on paraquat-exposed A549 cells via induction of Nrf2 and its downstream genes, Mol. Med. Rep. 8 (2013) 1852-1860.

[34] M.J. Davies, L.G. Forni, R.L. Willson, Vitamin E analogue Trolox C. E.S.r. and pulse-radiolysis studies of free-radical reactions, Biochem. J. 255 (1988) $513-522$. 